\title{
An Explanation of Movements In Short-Term Interest Rates
}

\author{
ALBERT E. BURGER
}

$\mathrm{V}$ IRTUALLY all central banks are concerned about movements in interest rates since, rightly or wrongly, the public usually regards the central bank as being responsible for such movements. An influential body of economic analysis also assigns considerable importance to the effects of movements in interest rates on economic activity. In addition, central banks have traditionally been concerned with the stability or viability of financial markets, where such stability and viability is usually viewed as being endangered by substantial fluctuations of interest rates. Consequently, in their policy deliberations the monetary authorities tend to give considerable weight to the possible impacts of their policy actions on interest rates.

It is important, therefore, to investigate the process by which interest rates are determined. This article is a modest step in that direction as it illustrates the manner in which a proposed explanation (hypothesis) of the movements in the short-term interest rate can be designed and tested. The purpose is not to develop a forecasting equation for the short-term interest rate, but to understand the process whereby interest rates are generated. The influence of key policy-determined variables, such as the growth rate of the monetary base and the money supply, are incorporated into the hypothesis.

A basic tenet of scientific investigation is that it is never proven that an hypothesis describes the one and only true world. Every hypothesis, if it is of any scientific value, must be formulated in such a manner that it can be falsifed by some set of observations. The more easily it can be falsified, the better the design of the hypothesis. Therefore, the result of any such process should be considered only tentative and subject to further testing. If the logical consequences of an hypothesis are not in agreement with the data, then it is back to the drawing board. Such a situation could result for any number of reasons, all of which must be carefully studied. If the hypoth esis is not rejected, we have not found the truth, but instead have taken just a very tentative step in our understanding of some economic process. Given this caveat emptor, we now proceed with the formal derivation and testing of an hypothesis designed to explain the month-to-month movements in the shortterm interest rate.

The first step in the design and testing of the hypothesis is to present a model of the market for short-term credit with specified constraints on the parameters of the model. The next step is to specify the observable data used to represent such general terms as "the state of economic activity," the "growth rate of money," "growth of prices," etc. The conjunction of the model, the constraints, and the specification of the empirical counterpart of the terms appearing in the model represent the hypothesis.

A reduced-form expression for the short-term interest rate is constructed and, using the restrictions on the structural parameters, test statements are derived. These test statements are then confronted with empirical observations to determine whether they are in "good agreement" with historical observations. After testing the hypothesis, a dynamic simulation of the short-term interest rate is performed using the reduced-form model for the interest rate.

\section{THI MODEL RND ITS RMPIRCA SPRGTWLATONS}

An algebraic formulation of the hypothesis is presented in Exhibit I. In the short-term credit market model, the demand for and supply of credit are divided into two parts - the private sector (equations 1 and 2) and the Government sector (equations 5 and 6). The private sector demand $\left(D^{p}\right)$ and supply $\left(S^{\mathfrak{w}}\right)$ of credit are influenced by such factors as the prevailing interest rate (i), the expected interest rate $\left(i^{\mathrm{e}}\right)$, the expected rate of change of prices $\left(\dot{\mathrm{P}}^{\mathrm{e}}\right)$, and the growth rate of the monetary base $(\dot{\mathrm{B}})$. The expected rate of change of prices is postulated to depend upon the prevailing long-run growth rate of money $(\dot{M})$, recent changes in prices $(\dot{\mathrm{P}})$, and the 
Exhibit I

\section{ALGEBRAIC FORMULATION OF THE HYPOTHESIS}

\section{Market for Short-Term Credit}

(1) private sector demand for eredit:

$$
\mathrm{Dp}=\mathrm{a}_{0}+\mathrm{a}_{1} \dot{\mathrm{i}}+\mathrm{a}_{2} \mathbf{i}+\mathrm{a}_{3} \dot{\mathrm{P}}_{\mathrm{e}}
$$

(2) private sector supply of credit:

$$
\mathrm{Sp}=\mathrm{b}_{0}+\mathrm{b}_{1} \mathrm{i}+\mathrm{b}_{2} \mathrm{ie}_{\mathrm{e}}+\mathrm{b}_{3} \dot{\mathrm{p}} \mathrm{e}+\mathrm{b}_{4} \dot{\mathrm{B}}
$$

(3) formation of interest rate expectations:

$$
i^{e}=c_{0}+c_{1} i_{t-1}+c_{2} i_{t-2}
$$

(4) formation of price expectations:

$$
\dot{\mathrm{p}}_{\mathrm{e}}=\mathrm{d}_{1} \dot{\mathrm{P}}+\mathrm{d}_{2} \dot{\mathrm{M}}+\mathrm{d}_{\mathrm{s}} \mathrm{U}+\mathrm{v}_{\mathrm{t}}
$$

(5) Government demand for credit: $D^{G}=e_{0}+e_{1} U$

(6) Government supply of credit: $S^{G}=\mathbf{f}_{0}+\mathbf{f}_{1} \mathrm{U}$

(7) total demand for credit: $\mathrm{D}=\mathrm{Dp}+\mathrm{D}^{\mathrm{a}}$

(8) total supply of credit: $S=S p+S^{a}$

(9) equilibrium condition: $\mathrm{D}=\mathrm{S}$

where:

$\mathrm{i}=$ short-term interest rate

ie $=$ expected short-term interest rate

$\dot{\mathrm{B}}=$ short-run rate of growth of the monetary base

$\dot{p}_{\mathrm{p}}=$ expected rate of change of prices

$\dot{\mathrm{P}}=$ lagged actual rate of change of prices

$\mathrm{U}=$ state of economic activity

$\dot{\mathrm{M}}=$ lagged long-rin growth rate of money

$v_{\mathrm{t}}=$ random variable

\section{Constraints}
(10) $a_{1}<0$
(11) $a z>0$
(I2) as $>0$
(13) $\mathrm{b}_{1}>0$
(14) b2 $<0$
(15) $\mathrm{bg}_{\mathrm{g}}<0$
(16) $\mathrm{b}_{4}>0$
(17) $\mathrm{c}_{1}>0$
(18) $c_{1}+c_{2}>0$
(19) $\mathrm{c}_{1}>\mathrm{c}_{2}$
(20) $\mathrm{d}_{1}>0$

(21) $\mathrm{d}_{2}>0$

(22) $\mathrm{d}_{3}<0$

(23) e $_{1}>0$

(24) $\mathrm{f}_{1}<0$

(25) $\left|\mathbf{a}_{3} \mathrm{~d}_{3}\right|>\left|\mathrm{f}_{1}-\mathbf{e}_{1}\right|$

(26) $\mathrm{d}_{2}>\mathrm{d}_{1}$

(27) $\left|\mathrm{d}_{1}\right|>\left|\mathrm{d}_{3}\right|$

(28) $\left|\mathrm{d}_{2}\right|>\left|\mathrm{d}_{3}\right|$

(29) $1-\mathrm{c}_{1}-\mathrm{c}_{2}>0$

30) $1+\mathrm{c}_{9}>0$

(31) $1+\mathrm{c}_{1}-\mathrm{c}_{2}>0$

Reduced Form for Interest Rate

(32) $i_{1}=A_{0}+A_{1} i_{t-1}+A_{2} i_{t-2}+A_{3} \dot{\mathrm{p}}+$ $A_{4} \dot{M}+A_{5} U+A_{6} \dot{B}+\varepsilon_{t}$

Test Statements for the Hypothesis
(33) $A_{1}>0$
(38) $\mathrm{A}_{5}<0$
(34) $A_{1}+A_{2}>0$
(39) $A_{6}<0$
(35) $A_{1}-A_{2}>0$
(40) $A_{4}-A_{3}>0$
(36) $A_{3}>0$
(41) $A_{3}+A_{5}>0$
(37) $A_{4}>0$
(42) $A_{4}+A_{5}>0$

current state of economic activity (U). Equation (4) essentially states that expectations about future movements in prices depend not only upon the past rate of change of prices, but also upon information about the long-run growth rate of money and the current state of economic activity. Price expectations are also hypothesized to depend upon certain random shocks that are represented by the term $v_{t}$ which appears in equation (4).

The expected interest rate $\left(i^{\mathrm{e}}\right)$ is stated to depend upon past values of the interest rate (equation 3 ). Current-month decisions to supply or demand credit are hypothesized to depend, among other things, upon the level of the short-term interest rate in the two previous months. The supply of credit is also stated to depend upon the growth of a liquidity variable, in this model represented by the growth of the monetary base.

The Government sector's demand for and supply of credit are specified as dependent upon the state of economic activity. Observation of the behavior of the Government sector suggests that its demand for credit also depends upon such things as its commitment to financing social programs, military developments in the world, and changes in tax laws. The hypothesis presented in this paper does not explicitly take these factors into account, but allows them to affect the intercept term that appears in the equation for the Government sector's demand for credit. Further development of the hypothesis might explicitly include these factors. However, primarily due to the diffculty of finding empirical counterparts to these concepts on a monthly basis, they were not explicitly taken into account.

\section{Constratus on the Variables}

The lower portion of Exhibit I presents a listing of the hypothesized constraints on the structural parameters of the model used to represent the shortterm credit market. These constraints state that the private sector's demand for credit $\left(D^{p}\right)$ depends positively upon the expected short-term interest rate $\left(\mathrm{i}^{\mathrm{e}}\right)$ and the expected rate of change of prices $\left(\dot{\mathrm{P}}^{\mathrm{e}}\right)$, and negatively upon the current short-term interest rate (i). The private sector's supply of credit $\left(S^{p}\right)$ depends positively on the rate of growth of the monetary base ( $\dot{B})$ and the current interest rate, and negatively on the expected rate of change of prices and the expected interest rate. The expected interest rate is postulated to depend positively upon past values of the interest rate. A series of past increases in the interest rate is hypothesized to generate expec- 
tations of still further upward movements in interest rates, thereby decreasing the amount of credit supplied at the current interest rate and increasing the quantity demanded at the current interest rate.

Price expectations are hypothesized to depend positively on recent changes in prices and the long-run growth rate of money, and negatively on the state of economic activity. For example, if prices have been rising rapidly in the current period, but the long-run trend growth of money has fallen and unemployment has risen, then the hypothesis implies that investors will not fully extrapolate into the future the current rapid growth of prices, but will modify their price expectations based on these latter two factors.

The Government sector's demand for credit is specified to depend positively, and the Government sector's supply of credit to depend negatively, upon the state of economic activity. For example, as the state of economic activity deteriorates, the expenditures of Government trust funds rise faster than their receipts and, hence, they reduce their purchases of Government securities.

As a further restriction upon the parameters of the model it is assumed that:

$$
\text { (25) }\left|a_{3} d_{3}\right|>\left|f_{1}-e_{1}\right|
$$

This assumption essentially states that the response of private demands for credit to changes in the state of economic activity are larger than the net Government reaction.

Furthermore, it is hypothesized that a one percentage point change in the long-run growth rate of money has a greater impact on the expected rate of inflation $\left(\dot{\mathrm{P}}^{\mathrm{e}}\right)$ than does a one percentage point increase in the rate of change of prices $(\dot{\mathbf{P}})$ :

(26) $\mathrm{d}_{2}>\mathrm{d}_{1}$

It is also hypothesized that a one percentage point change in the rate of change of prices has more of an effect on price expectations than does a one percentage point change in the state of economic activity (U):

$$
\text { (27) }\left|\mathrm{d}_{1}\right|>\left|\mathrm{d}_{3}\right|
$$

In addition, it is hypothesized that a one percentage point change in the long-run growth rate of money has more of an influence on the expected rate of inflation than does a one percentage point change in the state of economic activity:

$$
\text { (28) }\left|d_{2}\right|>\left|d_{3}\right|
$$

The specification of the signs and relative size of the coefficients on the structural parameters of the model is part of the hypothesis to be tested.

\section{Stubluty Conditions}

The equation for the expected interest rate may be rewritten as

$$
\mathrm{i}^{\mathrm{e}}-\mathrm{c}_{1} \mathbf{i}_{\mathrm{t}-1}-\mathrm{c}_{2} \mathbf{i}_{\mathrm{t}-2}=\mathrm{c}_{0},
$$

a second order difference equation. Hence, the necessary and sufficient conditions for the stability of the equilibrium value of $i$ and the condition $i^{e}=i$ requires further restrictions on admissable values for $c_{1}$ and $c_{2}:^{1}$

$$
\begin{aligned}
& \text { (29) } 1-\mathrm{c}_{1}-\mathrm{c}_{2}>0 \\
& \text { (30) } 1+\mathrm{c}_{2}>0 \\
& \text { (31) } 1+\mathrm{c}_{1}-\mathrm{c}_{2}>0
\end{aligned}
$$

\section{Reduced Form for the Short-Term Interest Rate}

Using the equilibrium condition that total demand for credit equals total supply $(D=S$ ) and substitut ing equations (3) and (4) into (1) and (2), the following reduced-form expression for the short-term interest rate is derived:

$$
\begin{aligned}
& \text { (32) } \dot{i}_{\mathrm{t}}=\mathrm{A}_{0}+\mathrm{A}_{1} \dot{\mathrm{i}}_{\mathrm{t}-1}+\mathrm{A}_{2} \dot{\mathrm{i}}_{\mathrm{t}-\mathrm{z}}+\mathrm{A}_{3} \dot{\mathrm{P}}+\mathrm{A}_{4} \dot{\mathrm{M}}+\mathrm{A}_{5} \mathrm{U} \\
& +\mathrm{A}_{6} \dot{\mathrm{B}}+\varepsilon_{\mathrm{t}} \\
& \text { where: } A_{13}=\frac{c_{0}\left(b_{2}-a_{2}\right)+\left(b_{0}-a_{0}\right)+\left(f_{0}-e_{0}\right)}{a_{1}-b_{1}} \\
& A_{1}=\frac{c_{1}\left(b_{2}-a_{2}\right)}{a_{1}-b_{1}} \\
& A_{2}=\frac{c_{2}\left(b_{2}-a_{2}\right)}{a_{1}-b_{1}} \\
& A_{3}=\frac{d_{1}\left(b_{3}-a_{3}\right)}{a_{1}-b_{1}} \\
& A_{1}=\frac{d_{2}\left(b_{3}-a_{3}\right)}{a_{1}-b_{1}} \\
& A_{5}=\frac{d_{3}\left(b_{3}-a_{3}\right)}{a_{1}-b_{1}}+\frac{f_{1}-e_{1}}{a_{1}-b_{1}} \\
& A_{6}=\frac{b_{4}}{a_{1}-b_{1}} \\
& \varepsilon_{t}=\left[\frac{b_{3}-a_{3}}{a_{1}-b_{l}}\right] v_{t}
\end{aligned}
$$

\section{Specification of Test Strtements}

The constraints (10) - (31) that were placed on the parameters of the credit market model logically imply signs and ordering relationships for the co-

1For a discussion of necessary and sufficient conditions for stability of a second order difference equation, see Samuel Goldberg, Introduction to Difference Equations (New York: John Wiley \& Sons, Inc., 1958), pp. $169 m 2$. 
efficients of the reduced-form equation for the shortterm interest rate. From the statement of the reduced form in equation (32) and from the set of conditions (10) - (31), the test statements numbered (33) - (42) are derived (Exhibit I). These test statements are used to test the hypothesis. The derivation of these test statements is shown in the Appendix to this article.

\section{ESTMATION OF THE REDUCED- FORM EOUATION: 196372}

The reduced-form equation (32) was estimated by ordinary least squares using monthly data. All data are seasonally adjusted, except the interest rate. The data that were used were those available at the end of May 1976.

The yield on prime four-to-six-month commercial paper is used as the measure of the short-term interest rate (i). It should be emphasized, however, that the purpose of this paper is not to build a model of the commercial paper market. The four-to-sixmonth commercial paper rate is taken as a proxy for the movement of all short-term interest rates. The unemployment rate is used as a proxy for the state of economic activity (U). The money stock is represented by the amount of demand deposits and currency. The long-run growth rate of money $(\dot{M})$ is represented by the annual rate of growth of money over the last 36 months. Prices are measured by the consumer price index. The rate of growth of prices $(\dot{\mathrm{P}})$ is measured as the annual rate of growth of the consumer price index over the previous six months. The monetary base is represented by the series published by the Federal Reserve Bank of St. Louis. The variable $\dot{B}$ is measured as the annual rate of change of the monetary base over the prior three months. ${ }^{2}$

The growth rates of the consumer price index and the money stock are lagged one period, based on the presumption that these are the data that credit market participants would have available in each period. Since the unemployment rate is taken as a general

$$
\begin{aligned}
& { }^{2} \dot{\mathrm{P}}=\frac{\mathrm{P}_{\mathrm{t}-1}-\mathrm{P}_{\mathrm{t}-\overline{\mathrm{i}}}}{\mathrm{P}_{\mathrm{t}-\vec{i}}}(2)(100)=\begin{array}{l}
\text { annual rate of change of con- } \\
\text { sumer price index over the pre- } \\
\text { vious six months. }
\end{array} \\
& \dot{\mathrm{M}}=\frac{\mathrm{M}_{\mathrm{t}-1}-\mathrm{M}_{\mathrm{t}-3 \bar{i}}}{\mathrm{M}_{\mathrm{t}-37}}(100) \div 3=\begin{array}{l}
\text { annual rate of change of money } \\
\text { over the previous } 36 \text { months. }
\end{array} \\
& \dot{\mathrm{B}}=\frac{\mathrm{B}_{\mathrm{t}}-\mathrm{B}_{\mathrm{t}-3}}{\mathrm{~B}_{t-3}}(4)(100)=\begin{array}{l}
\text { anntal rate of change of the monetary } \\
\text { base over the previous three months. }
\end{array}
\end{aligned}
$$

proxy for the state of economic activity, it is not lagged.

Equation (32) was first estimated over the 120 monthly observations from January 1963 through December 1972 . The results are as follows, where the numbers in parentheses are $t$-statistics:

$$
\begin{aligned}
& \text { (43) } \mathrm{i}_{\mathrm{t}}=.781+1.348 \mathrm{i}_{\mathrm{t}-1}-.500 \mathrm{i}_{\mathrm{t}-2}+.060 \dot{\mathrm{P}}+.064 \dot{\mathrm{M}}
\end{aligned}
$$

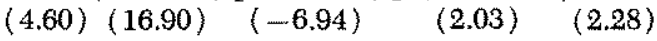

$$
\begin{aligned}
& -.066 \mathrm{U}-.029 \mathrm{~B} \\
& \begin{array}{ll}
(-2.96) & (-2.48)
\end{array} \\
& \mathrm{R}^{2}=.98 \quad \mathrm{SE}=.186 \quad \mathrm{DW}=1.99
\end{aligned}
$$

The estimated values of the coefficients of the reduced-form equation are in agreement with the test statements $(33)-(40)$ that are shown in Exhibit I.

$$
\begin{aligned}
& \mathrm{A}_{1}=1.348>0 \\
& \mathrm{~A}_{1}+\mathrm{A}_{2}=.848>0 \\
& \mathrm{~A}_{1}-\mathrm{A}_{2}=1.348+.500>0 \\
& \mathrm{~A}_{3}=.060>0 \\
& \mathrm{~A}_{4}=.064>0 \\
& \mathrm{~A}_{5}=-.066<0 \\
& \mathrm{~A}_{6}=-.029<0 \\
& \mathrm{~A}_{4}-\mathrm{A}_{3}=.064-.060>0
\end{aligned}
$$

\section{ESTMATION OE TUE REDUCED FORM EQUATION OVER ALTERNATIV PERTODS}

To investigate whether the hypothesis remains in good agreement with observed data when the sample period is altered, the reduced-form equation for the short-term interest rate was estimated over moving ten-year periods beginning with 1961 and ending in 1975 (six, ten-year periods). This procedure gives an indication as to whether the results reported so far are peculiar to the sample period $1 / 63-12 / 72$.

The results of estimating the reduced-form equation over alternative sample periods are given in Table 1 . Most of the results are in good agreement with the test statements $(33)-(40)$. However, there are two cases where the test statements do not appear to be in agreement with the data. The coefficient on the growth of the base in the period $1 / 66-12 / 75$ appears to violate test statement (39), where $A_{6}<0$. Even though the sign on the coefficient is negative, the t-statistic is very small, indicating that only at a very low level of probability can the hypothesis that $A_{6}=0$ be rejected. In the period $1 / 61-12 / 70$ the estimated coefficient on prices exceeds that on money, hence, $A_{4}-A_{3}<0$. This result suggests that the conjecture that the response of price expectations to the long-run growth of money exceeds the response to 


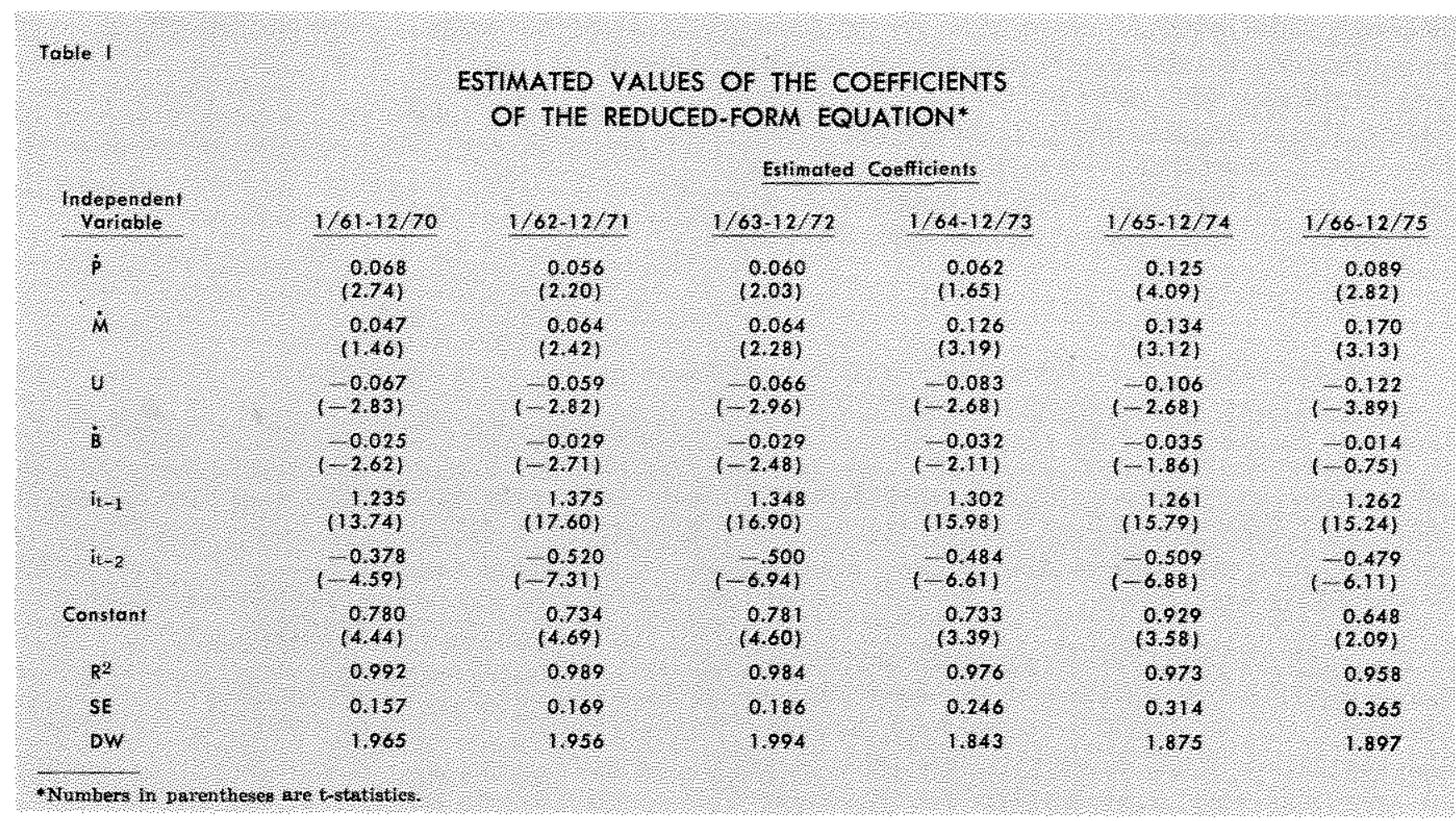

the past rates of change of prices is not correct in the earlier periods.

Test statements (41), where $A_{3}+A_{5}>0$, and (42), where $A_{4}+A_{5}>0$, involve comparing the relative size of the coefficient on the unemployment rate $\left(A_{5}\right)$ with the coefficient on prices $\left(A_{3}\right)$ and the long-run growth rate of money $\left(A_{4}\right)$. The unit of measurement of the unemployment rate differs from the units of measurement of prices and money, which are measured as annual rates of change. Therefore, beta coefficients are computed for $\mathrm{A}_{3}, \mathrm{~A}_{4}$, and $\mathrm{A}_{5}$, and are used to assess the test statements (41) and (42). ${ }^{3}$

The beta coefficients for each of the independent variables in the six sample periods are presented in Table II. For each of the sample periods, the beta coefficient for prices exceeds the beta coefficient for the unemployment rate. Hence, assumption (27), where $\left|\mathrm{d}_{3}\right|>\left|\mathrm{d}_{8}\right|$ (a one percentage point change in the past rate of change of prices has more effect on price expectations than does a one percentage point change in the unemployment rate), is judged to be in good agreement with the data.

3 The beta coefficient for an independent variable is defined as the coefficient for that variable multiplied by the standard deviation of the variable divided by the standard deviation of the dependent variable. See Arthur S. Goldberger, Econometric Theory (New York: John Wiley \& Sons, Inc., 1964) pp. 197-98; and Dick A. Leabo, Basic Statistics, 4th ed. (Homewood, Illinos: Richard D. Irwin, Inc., 1972), pp. 473-74.

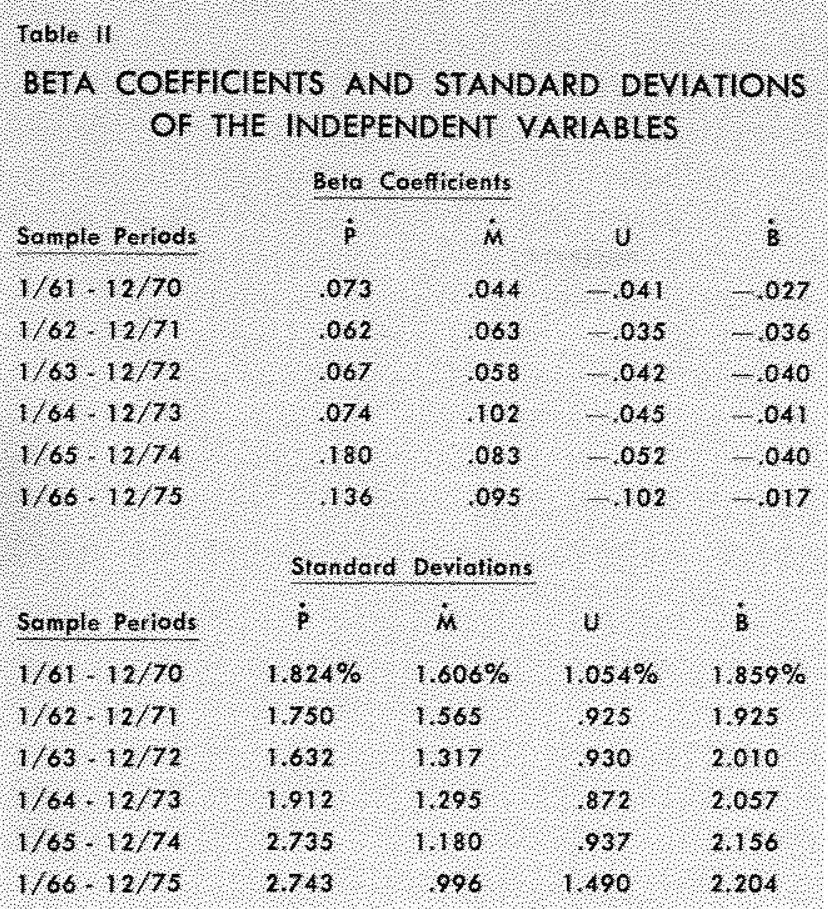

The beta coefficient for the long-run growth rate of money exceeds the beta coefficient for the un* employment rate in every period except the last sample period $1 / 66-12 / 75$. Hence, assumption (28), where $\left|\mathrm{d}_{2}\right|>\left|\mathrm{d}_{3}\right|$ (a one percentage point change in the long-run growth rate of money has a greater ef- 
fect on price expectations than does a one percentage point change in the unemployment rate), is in agreement with the data in all sample periods except the one that extends into 1975. The results in this last period raise serious questions about the acceptance of proposition (28). However, this latter period appears to have special characteristies that were not associated with the majority of the years in the earlier sample periods. For example, as shown in Table II, the standard deviation of the unemployment rate rises to 1.490 in the $1966-75$ period, compared to a standard deviation of between 0.872 and 0.937 in the four prior sample periods. These results indicate a need for careful further investigation of the difference between specific initial conditions in this latter period and the earlier periods.

\section{EXAMNATION OF SELCTED PROPERTES OF TIE MODE}

In this section certain specific properties of the reduced-form model of interest rate determination are examined. The testing of the hypothesis of interest rate determination that was presented in the first section of this paper is, of course, prior to the examination of the specific properties of the reducedform model.

First, the importance of the growth rates of prices, money, and base, and the level of the unemployment rate on the short-term interest rate is examined. The equilibrium short-term interest rate for each sample period is determined and then is decomposed to show the influence of each component.

Second, the dynamic properties of the model are examined. The model, as estimated over the period $1 / 63-12 / 72$, is simulated over the period $1 / 63-5 / 76$. In the simulation, the actual values of $\dot{\mathrm{P}}, \dot{\mathrm{M}}, \dot{\mathrm{B}}$, and $\mathrm{U}$ are used, and the model generates lagged values of the interest rate.

Dynamic simulation of the reduced-form model, which is derived from the hypothesis about interest rate determination, provides another chance to confront the hypothesis with the actual behavior of the interest rate. If such a dynamic simulation fails to replicate the general pattern of movements in the short-term interest rate, this does not in itself falsify the hypothesis. However, such a result would tend to raise questions about the specification of the model and, hence, influence most economists' willingness to tentatively accept the hypothesis from which the reduced-form model has been derived.
The reduced-form model of interest rate determination is specified such that random shocks to price expectations influence the behavior of the short-term interest rate. It will be recalled that the reducedform model for the interest rate (32) has a disturbance term $\left(\varepsilon_{t}\right)$. In the first dynamic simulation this term is set equal to zero. In the next simulation, shocks are introduced in specific months to illustrate the effects of such shocks on the dynamic behavior of the model. This procedure does not prove that shocks took place in the months in which they are introduced. It only shows that an observed pattern of sharp fuctuations in the short-term interest rate, that appears to be unrelated to the basic underlying movements of money, prices, base, and economic activity, is consistent with the hypothesis.

\section{Equhbribm Interest Rase}

The reduced-form equation, as estimated over the sample period $1 / 63-12 / 72$, may be written as follows:

$$
i_{t}-1.348 i_{t-1}+.500 i_{t-2}=8
$$

Therefore, the equilibrium solution for the interest rate, $i^{*}$, is given by:

$$
i^{*}=\frac{\delta}{1-1.348+.500}
$$

As shown in the Appendix, the solution for this second order difference equation satisfies the conditions for a stable equilibrium value of the interest rate.

To solve for the equilibrium value of the interest rate $\left(\dot{i}^{*}\right)$, the values of $\dot{\mathrm{P}}, \dot{\mathrm{M}}, \dot{\mathrm{B}}$, and $\mathrm{U}$ were set at their mean values for each sample period. As an example of the computation of the equilibrium interest rates, the following method was used for the $1 / 63-12 / 72$ period. The numbers in parentheses are the estimated coefficients for that period, as shown in Table I, and these coefficients are multiplied by mean growth rates for the respective independent variables, as shown in Table III.

$$
\begin{aligned}
& 3.303(.060)=.198 \\
& 4.756(.064)=.304 \\
& 4.653(-.066)=-.307 \\
& 5.458(-.029)=-.158 \\
& \text { Constant }=.781 \\
& .818 \\
& \delta=.818
\end{aligned}
$$

4A stable equilibrim is defined as one for which any displace. ment from equilibrium is followed by a sequence of values of the interest rate which again converge to an equilibrium. See Samuel Goldberg, Introduction to Difference Equations, $\mathrm{pp}$. $169-70$. 


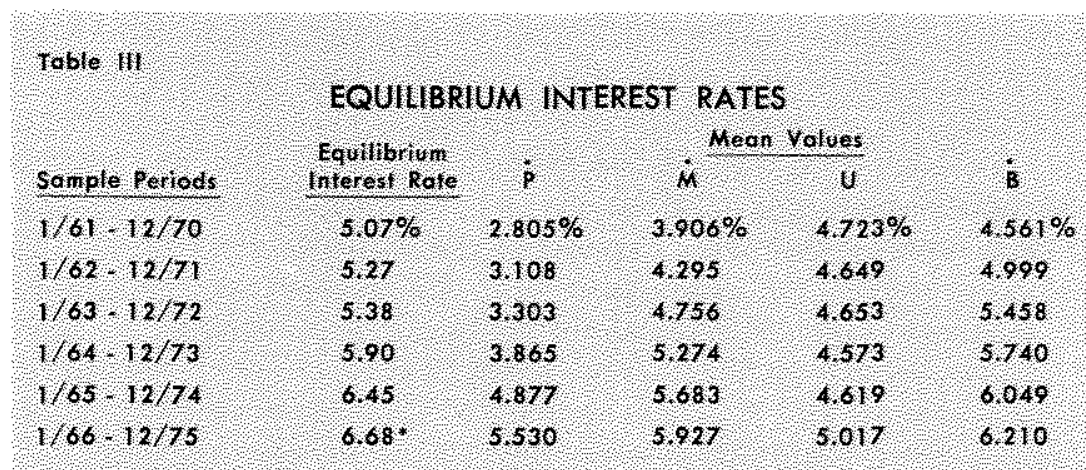

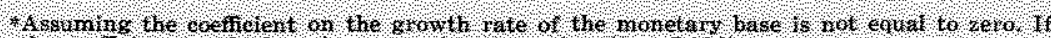

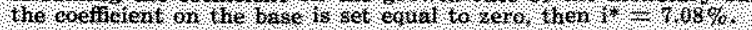

$$
\mathrm{i}^{\circ}=\frac{.818}{1-1.348+.500}=\frac{.818}{.152}=5.38 \%
$$

This procedure was repeated using the estimated coefficients for each sample period and setting the values of $\dot{\mathrm{P}}, \dot{\mathrm{M}}, \dot{\mathrm{B}}$, and $\mathrm{U}$ at their mean values. These results are shown in Table III.

The mean values of the independent variables were chosen so as to approximate a consistent set of values for these variables. For example, using past relationships, it would seem inappropriate to assume that an equilibrium growth rate of prices of, say, 9 percent would be consistent with a 2 percent equilibrium growth rate of money, or that an 8 percent equilibrium growth rate of base would be consistent with 2 percent money growth.

\section{Relative Mmporance of $\dot{B}, \tilde{M}, \dot{B}, U$ on Interest Rates}

Each of the estimated coefficients of the rem duced-form equation was multiplied by the respective mean growth rate of that variable to which the coefficient is attached. For example, $A_{3}$ (the estimated coefficient of the growth rate of prices) was multiplied by the mean growth rate of prices.

If we let $\delta_{1}=A_{3} \cdot$ (mean growth rate of prices) $\delta_{2}=A_{4} \cdot$ (mean growth rate of money)

$\delta_{3}=A_{5} \cdot$ (mean unemployment rate)

$\delta_{4}=A_{6} \cdot$ (mean growth rate of base) $\delta_{0}=A_{0}$

then the equilibrium interest rate $\left(i^{*}\right)$ can be cxpressed as:

$$
\begin{gathered}
\mathrm{i}^{*}=\frac{\delta_{0}}{1-A_{1}-A_{2}}+\frac{\delta_{1}}{1-A_{1}-A_{2}}+\frac{\delta_{2}}{1-A_{1}-A_{2}} \\
+\frac{\delta_{3}}{1-A_{1}-A_{2}}+\frac{\delta_{4}}{1-A_{1}-A_{2}}
\end{gathered}
$$

The relative contribution of each factor to the equilibrium interest rate in each sample period is given in Table IV. For comparison purposes, the results in Table IV should be read from left to right across the Table. Each row in the Table shows the changing influence of each factor as all factors are assumed to vary in a consistent manner.

The results of this procedure indicate that the major factors accounting for the rise in the equilibrium interest rate from 5.07 percent in $1 / 61-12 / 70$ to 6.68 percent in $1 / 66-12 / 75$ were the accelerations in the mean growth rates of prices and the long-run growth rate of money. The mean value of the longrun growth rate of money rose from 3.9 percent in $1 / 61-12 / 70$ to 5.9 percent in the last sample period. Associated with this increase in the mean growth rate of money was an increase in the mean growth rate of prices from 2.8 percent to 5.5 percent. Since in this model $\dot{\mathrm{P}}$ and $\dot{\mathrm{M}}$ are the major factors influencing the expected rate of change of prices, these results indicate that a rise in the expected rate of inflation is a major influence operating to raise the equilibrium interest rate.

These results also indicate that the liquidity effect of a rise in the growth rate of the monetary base has a small effect relative to the effects of the associated changes in other factors. As the average growth rate of the monetary base increased across the sample periods, the average growth rate of money also increased, and consequently, the average growth rate of prices increased. The combined effect of the accelerated growth rates of money and prices swamped the corresponding liquidity effect of the faster growth rate of the base on the short-term interest rate.

\section{Dynamic Simulations}

In this section the results of two dynamic simulations are reported. The simulations were performed using the reduced-form equation for the short-term interest rate as estimated over the period $1 / 63-12 / 72$. Then, using these estimated coefficients and the actual values of $\dot{P}, \dot{M}, U$, and $\dot{B}$, and setting $\varepsilon_{t}=0$, the monthly pattern of the short-term interest rate was simulated for the period 1/63-5/76. The period $1 / 63-12 / 72$ was an in-sample simulation, and the period $1 / 73-5 / 76$ was an out-of-sample simulation. Values of $\dot{\mathrm{P}}, \dot{\mathrm{M}}, \mathrm{U}$, and $\dot{\mathrm{B}}$ vary over the period and 


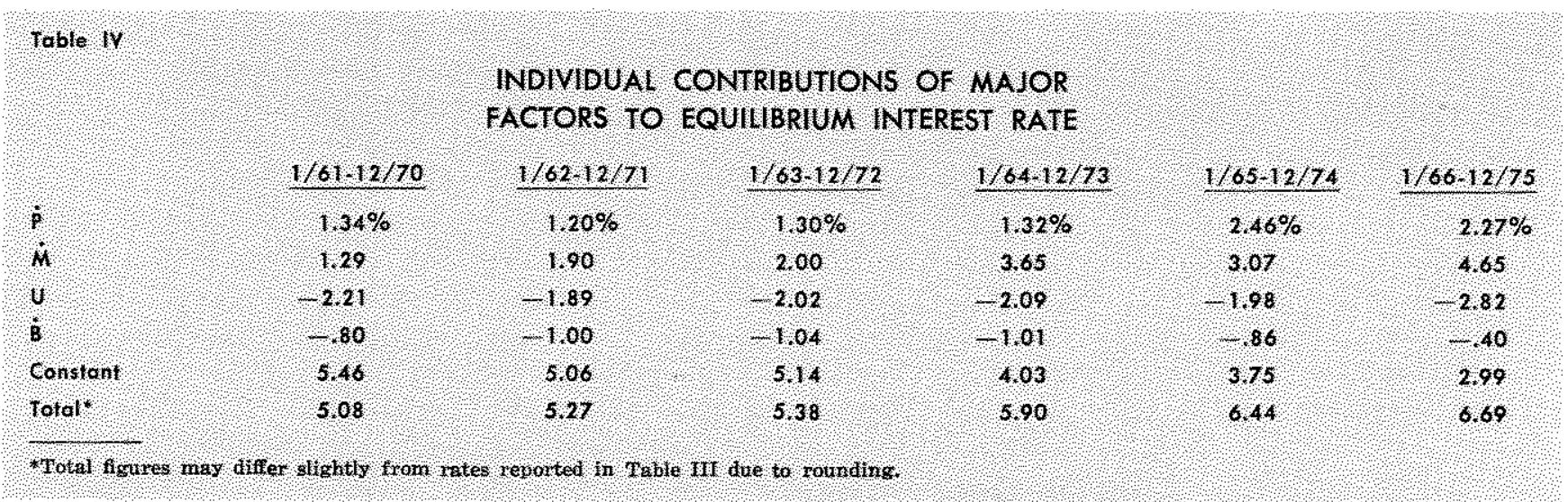

lagged values of the interest rate are those generated by the model. The results of this simulation are shown in Chart I.

As can be seen from the chart, the simulated pattern of the commercial paper rate follows the general contours of the actual pattern of the commercial paper rate. This relation is quite close in the period 1963-72. During this period the mean error between the actual interest rate and the simulated interest rate was about 4 basis points, and the root mean squared error was about 45 basis points. These and other statistics for comparing the performance of the simulation are given in Table $\mathrm{V}$.

As the simulation is carried on from early 1973 through mid-1976, the statistics used to evaluate the performance of the simulation show a marked rise in the errors. As shown in Table $V$, the mean error for the period 1973-75 rises to 68 basis points, and the root mean squared error rises to 145 basis points.

Two points should be made about the simulation results from the 1973 through mid-1976 period. First, as the simulation is carried on from the start of 1973 through May 1976, the simulated values of the shortterm interest rate continue to reproduce the general pattern of the short-term interest rate. The simulated rate rises sharply from early 1973 through late 1974 and then falls sharply into 1975. However, in contrast to the smooth pattem of the simulated interest rate, the actual interest rate displayed a series of very sharp fluctuations in this period. For example,

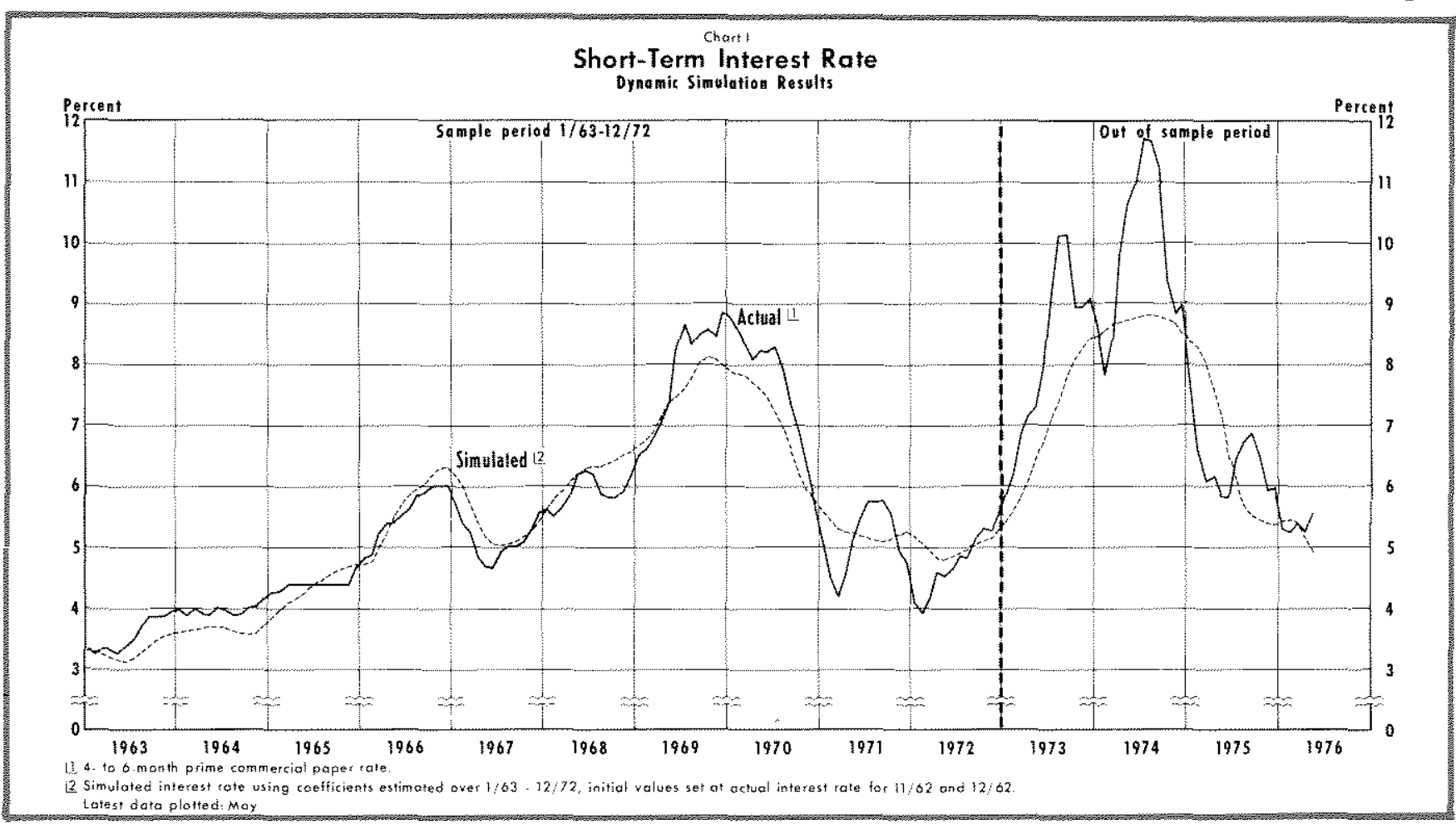




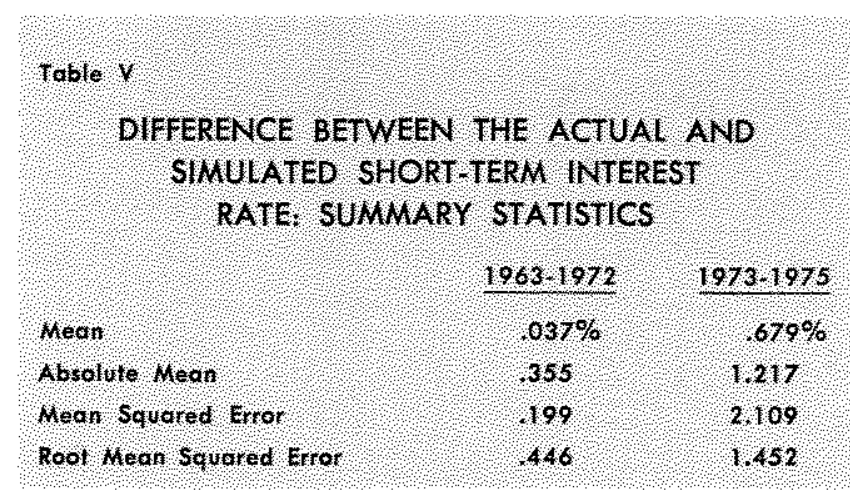

the actual interest rate (commercial paper rate) rose from about 6 percent in early 1973 to above 10 percent in September 1973, fell to about 8 percent in early 1974, then rose to about 12 percent in July 1974, and fell to about 6 percent in March 1975.

Second, the actual interest rate does not continue to diverge from the simulated value of the interest rate. For short periods the actual value moves sharply above the simulated rate, but then it rapidly converges back to the pattern of the simulated rate. By the end of 1975 and into 1976 , the actual and simulated rates are again moving closely together.

Therefore, the question arises as to what accounts for these sharp short-run deviations of the actual interest rate from the simulated path of the interest rate. To begin, first note that in the initial simulation $\varepsilon_{t}$ was set equal to zero. In other words, no random shocks to price expectations were introduced into the simulation. Given the dynamic characteristics of the reduced-form equation for the interest rate, adding shocks (setting $\varepsilon_{\mathrm{t}} \neq 0$ ) will affect the simulated pattern of the interest rate. For example, if $\varepsilon_{t}$ is set at a value greater than zero in one period and then allowed to return to zero in every following period, the effect on the simulated interest rate will appear, not only in the first period, but also in following periods. Eventually the simulated interest rate will converge back to the level determined by the growth rates of money, prices, base, and the level of the unemployment rate. However, in the interim, the simulated rate will have deviated sharply from that generated by setting $\varepsilon_{t}=0$.

Consequently, a second simulation was performed to illustrate the behavior of the simulated interest rate when periodic shocks are introduced. The simulation was begun in $1 / 73$ and the initial values for the interest rate were set at their actual values for November and December 1972. Then, shocks were introduced in selected months, and the system was

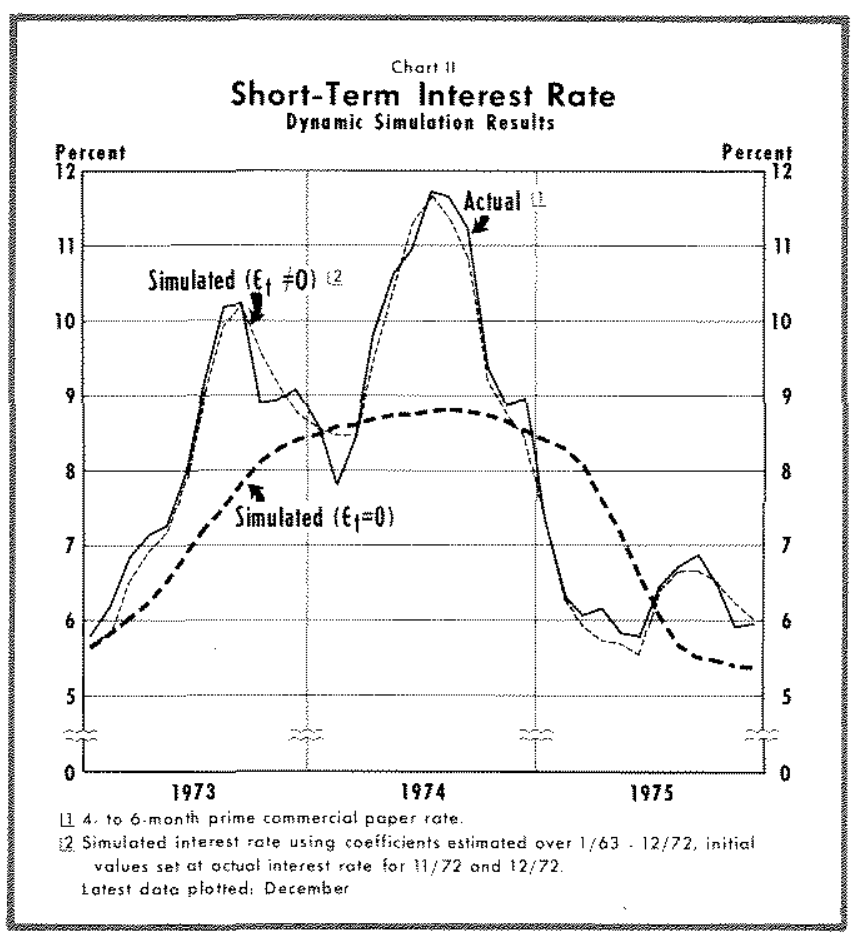

allowed to adjust to the shocks. In many months $\varepsilon_{\mathrm{t}}$ was set equal to zero. Then periodically $\varepsilon_{t}$ was set at a value greater or less than zero. The results of this simulation, one in which periodic shocks were introduced in selected months along with the changing growth rates of prices, money, base, and the unemployment rate, are shown in Chart II and Table VI. Chart II shows that by selectively introducing periodic shocks, a simulated pattern of the shortterm interest rate can be generated that closely approximates the actual behavior of the short-term interest rate.

The exact causes of such shocks are not well understood and have not been the subject of much empirical investigation. One example of such a shock to price expectations would be the announcement of the oil embargo that occurred in 1973. This development quite likely affected price expectations, but was not incorporated in information about the past rate of change of prices, money, or the state of economic activity. This development probably had recurring effects on price expectations each time OPEC met to set the price of oil and each time the U.S. Government announced a new program to combat the "energy crisis."

As another example of how such shocks might originate, consider the case where the Federal Government announces that it expects to run a deficit over the next few years that, by past standards, is 


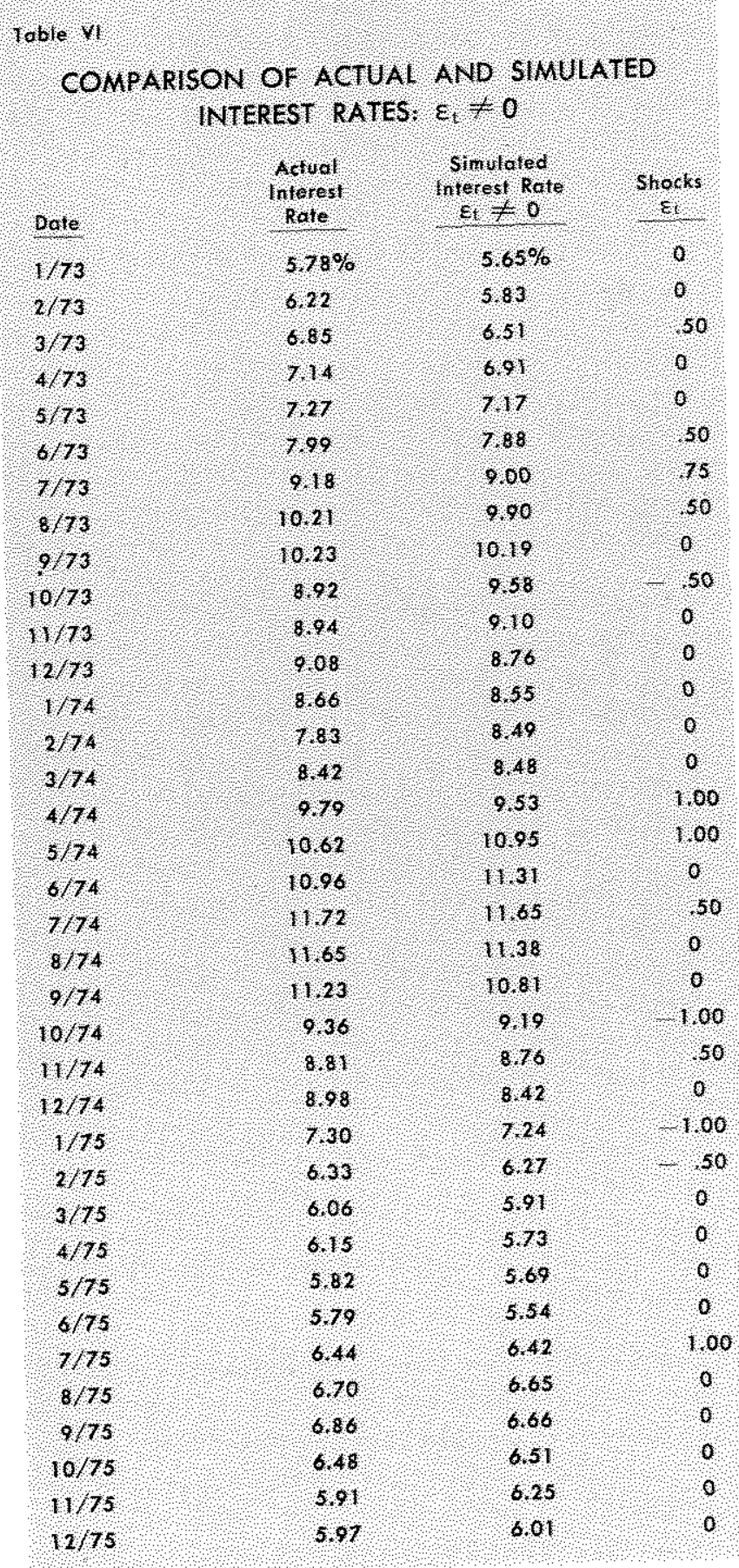

very large. Consequently, there is a great amount of discussion in the financial press and among economic forecasters concerning the implications of this pattern of projected large deficits. Suppose further that the consensus opinion is that these deficits imply that the central bank will respond by sharply increasing its purchases of Government securities; hence, the growth of money will be much more rapid than was previously observed. This chain of events could conceivably lead to a substantial shock to price expectations. In other words, the future rate of inflation would now be expected to be greater than what individuals had expected given the past rate of change of prices and the long-run growth of money.

Suppose that after a period of time, even though there are large deficits, the money supply does not accelerate, and the Federal Reserve firmly announces that it does not intend to allow an acceleration in money growth. Consequently, this may result in a revision of price expectations in the downward direction $\left(\varepsilon_{\mathrm{t}}<0\right)$ and, hence, a substantial fall in interest rates may occur.

These results contain the interesting implication that the basic mechanism generating interest rates may not have changed radically during the period 197375. Rather, a series of shocks occurred during this latter period which resulted in much greater variation in interest rates than can be accounted for by the changing growth rates of money, base, prices, and the level of the unemployment rate.

\section{SUMMART AND CONCLUSTONS}

An hypothesis designed to explain the movements in the short-term interest rate has been presented in this article. The hypothesis was given explicit form in the mathematical representation of the short-term credit market presented in equations (1) - (9). Signs and relative sizes were attached to the parameters of the structural equations. From the structural equations a reduced-form expression for the interest rate was derived. Empirical counterparts to the terms appearing in the reduced-form equation were specified. All of these steps are integral parts of the hypothesis.

Other economists might favor a different specification of the short-term credit market. Also, they might contend that "the short-term interest rate" should be mapped into the empirical counterpart of the Treasury bill rate instead of the commercial paper rate, or that "prices" should be represented by the wholesale price index rather than the consumer price index, or that the "state of economic activity" is not well represented by the unemployment rate. These assertions can only be evaluated when they are given definite form by respecifying the hypothesis and deriving new test statements that can be confronted with empirical evidence.

No attempt was made to justify a priori the specification of the model, the assignment of signs to the parameters of the model, or the use of specific 
empirical counterparts to the theoretical terms that appear in the model. Instead, the hypothesis was formulated in such a manner that statements could be derived from the hypothesis that were capable of being falsified by observed data. The potential falsifiers of the hypothesis were the test statements (33). (42). These test statements are derivable consequences of the hypothesis. Conceivably, some or all of the test statements (33) - (42) could have turned out to be not in agreement with the data. This could have resulted from any of the steps involved in constructing the hypothesis. Such results provide evidence against the hypothesis, hence, requiring careful analysis of the cause of the falsification and possible reformulation of one or more parts of the hypothesis.

The test statements were generally in good agreement with the observed data. These results were not specific only to the initial sample period that was chosen, but also held as the sample period was varied over fifteen years. This does not mean the hypothesis is a "true" representation of the determinants of the short-term interest rate. It only means that, subject to a continuation of more rigorous testing of the hypothesis, it might be tentatively considered as a representation of the process whereby the shortterm interest rate is determined.

As was pointed out in the discussion of the test results, there were a few cases where some of the test statements did not agree with the data. These are important results and cast doubt on parts of the hypothesis. Hence, they require careful further investigation. Two of these results were peculiar to the sample period 1966-75. It was mentioned that the latter years of this period had special characteristics that were "different" from the earlier years of the sample period. This assertion was developed in more detail in latter sections of the paper.

After testing the hypothesis, the reduced-form model for the interest rate was used to examine certain selected properties of the proposed explanation of the movements in the interest rate. An equilibrium interest rate was derived for each of the sample periods. These results indicated a fairly substantial rise in the equilibrium interest rate as the sample period was changed. This rise was attributed primarily to the increased average long-run growth rate of money and the faster average growth of prices operating through their effects on price expectations.

Dynamic simulations of the interest rate were performed using the reduced-form model for the interest rate. The results of these simulations indicated the possibility of recurring shocks in the 1973-75 period. Consequently, an alternative simulation was performed where shocks were introduced in selected months. It was shown that such a procedure resulted in a pattern of the simulated interest rate which closely approximated the pattern of the actual interest rate. These results led to the conjecture that the underlying mechanism generating interest rates was unchanged in the last few years. In other words, the evolution of the short-term interest rate continued to depend upon the same basic factors - the influence of the growth rate of money, prices, the state of economic activity, and the growth of the base. Sharp divergences from this path were accounted for by periodic shocks.

At the start of this paper it was stated that it was not the purpose of this article to develop a pure forecasting model for the short-term interest rate. The simulation results reported in the paper, however, have some interesting implications for forecasting interest rates. They indicate that even if an individual were lucky enough to correctly predict the future growth rates of prices, money, monetary base, and the unemployment rate, this might only permit a forecast of the general contour of the future path of interest rates. In periods such as the last few years, periodic shocks may occur which, according to the model developed in this paper, would result in sharp upward or downward movements in interest rates. Without knowledge of the timing and magnitude of these shocks, which are usually assumed to be randomly distributed over a sufficiently long period, it would not be possible to closely forecast for an extended period the actual path of the short-term interest rate.

These results also point out difficulties that can result for a central bank if it tries to tightly control short-run movements in interest rates. Suppose there is a shock that raises price expectations and, consequently, interest rates. The dynamic properties of the reduced-form interest rate model derived from the hypothesis presented in this paper show that such shocks result in a sharp rise in the interest rate. However, in the absence of future shocks, the interest rate will not continue to rise indefinitely, but after a time will begin to fall and converge back toward the level determined by the growth rates of prices, money, base, and the state of economic activity. If, however, the central bank takes aggressive action to halt the rise in rates, then inter- 
est rates will not converge back to the level determined by the previous growth rates of prices, money, and base, but will converge to a new higher level.
Also, such a process raises the possibility of further positive shocks to price expectations and substantial further upward pressures on interest rates.

\section{APPENDIX I}

\section{DERIVATION OF TEST STATEMENTS}

$$
\text { (33) } A_{1}>0
$$

$A_{1}=\frac{c_{1}\left(b_{2}-a_{2}\right)}{a_{1}-b_{1}}$

(17) $\mathrm{c}_{1}>0$

(14) $\mathrm{b}_{2}<0$

(11) $a_{2}>0$

Therefore: $c_{1}\left(b_{2}-a_{2}\right)<0$

(10) $\mathrm{a}_{1}<0$

(13) $b_{1}>0$

Therefore: $\left(a_{1}-b_{1}\right)<0$

Therefore: $A_{I}>0$

$$
\begin{gathered}
\text { (34) } A_{1}+A_{2}>0 \\
A_{1}+A_{2}=\left(c_{1}+c_{2}\right)\left(\frac{b_{2}-a_{2}}{a_{1}-b_{1}}\right) \\
\text { Since: }\left(a_{1}-b_{1}\right)<0 \\
\text { Since: }\left(b_{2}-a_{2}\right)<0 \\
\text { Therefore: } \frac{b_{2}-a_{2}}{a_{1}-b_{1}}>0 \\
\text { (18) } c_{1}+c_{2}>0
\end{gathered}
$$

Therefore: $\mathrm{A}_{1}+\mathrm{A}_{2}>0$

$$
\begin{gathered}
\text { (35) } A_{1}-A_{2}>0 \\
A_{1}-A_{2}=\left(c_{1}-c_{2}\right)\left(\frac{b_{2}-a_{2}}{a_{1}-b_{1}}\right) \\
(19) c_{1}>c_{2}
\end{gathered}
$$

Therefore: $c_{1}-c_{2}>0$

Since: $\left(\frac{b_{2}-a_{2}}{a_{1}-b_{1}}\right)>0$

Therefore: $A_{1}-A_{2}>0$

$$
\begin{aligned}
& \qquad \begin{array}{l}
\text { (36) } A_{3}>0 \\
A_{3}=\frac{d_{1}\left(b_{3}-a_{3}\right)}{a_{1}-b_{1}} \\
(20) d_{1}>0 \\
(12) a_{3}>0 \\
\text { (15) } b_{3}<0
\end{array} \\
& \text { Therefore: } d_{1}\left(b_{3}-a_{3}\right)<0 \\
& \text { Since: } a_{1}-b_{1}<0 \\
& \text { Therefore: } A_{3}>0
\end{aligned}
$$

$$
\text { (37) } \mathrm{A}_{4}>0
$$

$$
A_{4}=\frac{d_{2}\left(b_{3}-a_{3}\right)}{a_{1}-b_{1}}
$$

$$
\text { (21) } d_{2}>0
$$

Therefore: $d_{2}\left(b_{3}-a_{3}\right)<0$

Since: $a_{1}-b_{1}<0$

Therefore: $\mathrm{A}_{4}>0$

$$
\text { (38) } \mathrm{A}_{5}<0
$$

$A_{5}=\frac{d_{3}\left(b_{3}-a_{3}\right)+\left(f_{1}-e_{1}\right)}{a_{1}-b_{1}}$

(22) $\mathrm{d}_{3}<0$

(25) $\left|a_{3} d_{3}\right|>\left|f_{1}-e_{1}\right|$

Therefore: $-a_{3} d_{3}+\left(f_{1}-e_{1}\right)>0$

Since: $d_{3} b_{3}>0$

Therefore: $d_{3}\left(b_{3}-a_{3}\right)+\left(f_{1}-e_{1}\right)>0$

Since: $a_{1}-b_{1}<0$

Therefore: $\mathrm{A}_{5}<0$ 


$$
\text { (39) } \mathrm{A}_{6}<0
$$

$$
A_{6}=\frac{b_{4}}{a_{1}-b_{1}}
$$

(16) $b_{4}>0$

Since: $a_{1}-b_{1}<0$

Therefore: $A_{6}<0$

$$
\begin{aligned}
\text { (40) } A_{4}-A_{3} & >0 \\
A_{4}-A_{3} & =\left(d_{2}-d_{1}\right)\left(\frac{b_{3}-a_{3}}{a_{1}-b_{1}}\right) \\
(20) d_{1} & >0 \\
(21) d_{2} & >0 \\
\text { (26) } d_{2} & >d_{1}
\end{aligned}
$$

Therefore: $\left(d_{2}-d_{1}\right)>0$

Since: $\left(\frac{b_{3}-a_{3}}{a_{1}-b_{1}}\right)>0$

Therefore: $A_{4}-A_{3}>0$

$$
\text { (41) } A_{3}+A_{5}>0
$$

$$
A_{3}+A_{5}=\left(d_{1}+d_{3}\right)\left(\frac{b_{3}-a_{3}}{a_{1}-b_{1}}\right)+\left(\frac{f_{1}-e_{1}}{a_{1}-b_{1}}\right)
$$

(27) $\left|d_{1}\right|>\left|d_{3}\right|$

Therefore: $\mathrm{d}_{1}+\mathrm{d}_{3}>0$

Since: $\left(\frac{b_{3}-a_{3}}{a_{1}-b_{1}}\right)>0$

Since: $\left(\frac{f_{1}-e_{1}}{a_{1}-b_{1}}\right)>0$

Therefore: $A_{3}+A_{5}>0$

$$
\begin{aligned}
& \text { (42) } A_{4}+A_{5}>0 \\
& A_{4}+A_{5}=\left(d_{2}+d_{3}\right)\left(\frac{b_{3}-a_{3}}{a_{1}-b_{1}}\right)+\left(\frac{f_{1}-e_{1}}{a_{1}-b_{1}}\right) \\
& \text { (28) }\left|d_{2}\right|>\left|d_{3}\right|
\end{aligned}
$$

\section{APPENDIX II}

\section{STABILITY CONDITIONS FOR EQUILIBRIUM INTEREST RATE}

Given a difference equation of the form:

$$
\begin{gathered}
y_{k+2}+z_{1} y_{k+1}+z_{2} y_{k}=\delta \\
\delta=\text { constant }
\end{gathered}
$$

the necessary and sufficient conditions for a stable equilibrium are given by:

$$
\begin{aligned}
& 1+z_{1}+z_{2}>0 \\
& 1-z_{2}>0 \\
& 1-z_{1}+z_{2}>0
\end{aligned}
$$

Rewriting the equation for the interest rate as:

$$
i_{z}+z_{1} i_{t-1}+z_{2} i_{t-2}=\delta
$$

where,

$$
\begin{aligned}
& Z_{5}=-A_{1} \\
& z_{2}=-A_{2}
\end{aligned}
$$

the stability conditions for $1 / 62-12 / 73$ are given as:

$$
\begin{aligned}
& 1+(-1.348)+.500>0 \\
& 1-.500>0 \\
& 1-(-1.348)+.500>0
\end{aligned}
$$

